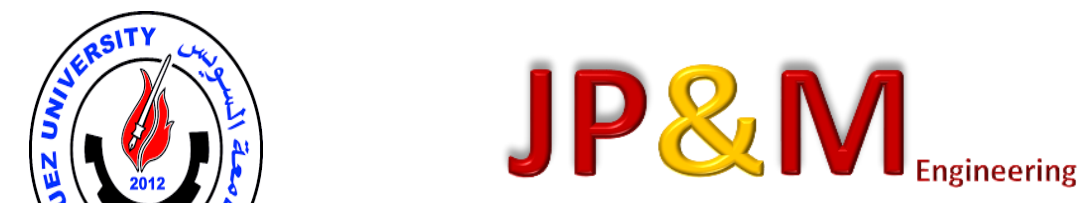

Journal of Petroleum and Mining Engineering

\title{
Fuzzy Logic-Based Analytic Hierarchy Process and Principal Component Analyses for Optimal Surface Mining Techniques
}

\author{
.Gomaa, E.*a,b, Arafat, A. A. ${ }^{a, b}$ and El-Nagdy, K. A. ${ }^{a, b}$ \\ ${ }^{a}$ Mining Engineering Dept., Faculty of Petroleum and Mining Engineering, Suez University, Suez, Egypt \\ ${ }^{b}$ Civil Engineering Dept., Faculty of Engineering, Taif University, Taif, Kingdom of Saudi Arabia \\ *ehabgomaa7@gmail.com
}

\section{Article Info}

Received 29 Sep. 2021 Revised 21 Nov. 2021 Accepted 30 Nov. 2021

\section{Keywords}

Surface mining, Rock breakage techniques, Fuzzy Analyses Hierarchical Process and Fuzzy Principal Component Analyses.

\begin{abstract}
In this paper, seven production methods including drilling and blasting are evaluated concerning technical, environmental, and economical aspects. These production techniques are wheel excavator, hydraulic excavator, surface miner, hydraulic hammer, bulldozer, and face miner. This study is carried out to find the best technique, that may alternate to the classical drilling and blasting method. However, the use of such classical production method may be the only option for some quarry operators. Various comparison aspects are investigated concerning the welfares of these systems, the relation between the potential improvement of the ecological effects on the one hand and the technological potential, and the costs on the other. Two different statistical analyses that are the Fuzzy Method Analyses Hierarchical Process (AHP) and Principal Component Analyses (PCA) are applied in this assessment. The final evaluation of the two mathematical models is matched closely, and it proves that the drilling and blasting is the most efficient method then come after it bucket wheel excavator, hydraulic excavator, surface miner, hydraulic hammer, bulldozer, and face miner, respectively. The range of competency among these techniques regarded to drilling and blasting efficiency is ranged from $78.5 \%$ to $20 \%$.
\end{abstract}

\section{Introduction}

The high demand for raw materials and the shrinking number of economically mineable deposits challenges the mining industry to increase the demand for innovative, economical, efficient, and environmentally friendly exploitation methods. As a result, many approaches are applied today to rock break-in surface mining, such as drilling and blasting, cutting, breaking, ripping, and milling techniques, as shown in Figure (1) [1-3]. It is well known that all the different rock breakage operations no way to be compared to the drilling and blasting operations, because they are of course the most efficient and cheapest mining methods, especially in the case of hard rocks. But in many cases, mining companies are concerned with the environmental effects resulting from mining operations and they are forced to search for alternative mining operations for some suitable processes for mining methods in the mine, regardless the cost $[4,5]$. In the surrounding and adjacent to the mines, companies may often have to pay huge amounts of compensation for the damages resulting from the explosions to the community surrounding the mines, and therefore, they are looking for alternatives in some areas to replace the blasting operations. Consequently, this study does not aim to derive a better mining method than blasting, but it aims to reach the best alternative methods that can be used as an alternative to blasting for special circumstances of mining conditions [4,6]. The appropriate mining operation is not only the low-cost operation method but also that is technically applicable for the ore, suitable for the ground conditions, and Safe for the surrounding environment. Then there are more than one suitable option and the main task, in this case, is how to choose the best alternative which has the fewest problems among them $[4,7,8]$.

There are earlier studies in the mining production methods without the use of explosives and give the important question is what are the true benefits of the explosive techniques with all the environmental effects and the technological potential as well as the costs [1,2]. Also, there is a review that investigates both explosive and nonexplosive rock breakage methods to see the potential negative effects of the conventional methods. Also discuss the advantages of modern alternative rock breakage methods, including environmental protection and focused on safety during the rock breakage process [7]. The technical options will be examined under commercial aspects and on the basis of the methodology defined. This will include both static and dynamic cost analyses, with the static cost analysis examining the capital and 
operating costs. The dynamic cost analysis will be depending on the mining tools company. Non-viable methods will be disregarded in all future examinations. The commercial assessment will be followed, if possible, by a quantification of the environmental effects by way of input-output analysis, during which the environmental effects will be considered.

The most popular technique that answers decisionmaking problems is the analytical hierarchy process (AHP). However, AHP is ineffective when applied to ambiguous problems like the uncertainty of the criteria parameters $[9,10,11,12]$. For accommodating the uncertainty of the factors, AHP is integrated with fuzzy logic $[13,14]$. Sensitivity analysis is an essential component of fuzzy-AHP decision-making models [15]. The sensitivity analysis measures the consistency in selecting the best alternative in different conditions $[15,16,17]$. The final priorities of the alternatives are heavily dependent on the weights associated with the main criteria parameters [18]. The selection of mining equipment depends on multiple factors. Thus, it is important to analyze the degree of decision-making due to either a change in a factor's uncertainty level or a decision maker's attitude [4,6]. Sensitivity analysis provides information about an alteration in the ranking of the alternatives. The sensitivity analysis of different decision-making models has been performed in different fields, but very few in selecting mining equipment $[19,20]$. The actual mining operations comprise the extraction system as refers to all equipment necessary to exploit and the partial operations, such as digging out the rock or loosening, loading, hauling or conveying, and pre-crushing. The mining operations are called by the direction progress such as vertical or horizontal, (parallel mining, surface bench mining, side-to-side mining).

The most important consideration is the geotechnical (digging height, soils type, output rate, and consumption power), economical (production cost, maintains cost and final investments), and environmental parameters, (dust, Noise, emissions of gases, cumulative energy and vibration) taken into account in this study. However, the geological parameters could be neglected because of the similarity of all soil types in the different opencast mining. The term extraction technique refers to the way how the rock is loosened, which can be done either by drilling and blasting or by a technique without the use of explosives by evaluating the geotechnical, economical, and environmental parameters. The present study analyzes the decisionmaking results in selecting the best surface mining rock breakage technique using the proposed AHP and principal component analyses (PCA) models under different fuzzification factors and decision-making attitudes. The model performance was analyzed by changing the uncertainty levels of the factors from minimum to maximum in different decision-making

attitudes, i.e., optimistic, pessimistic, and unbiased. The annual production capacity of the surface mine to be assessed has been specified $[4,7,8]$. The production capacity for each extraction technique is established based on the deposit or the rock formation with its bonding or rock properties $[3,4]$.

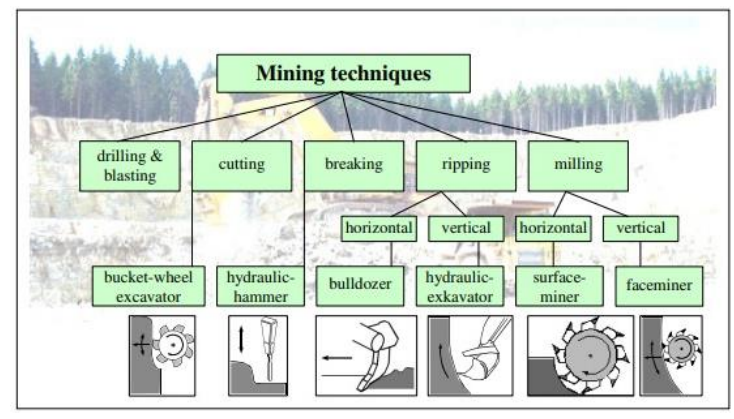

Figure 1 Extraction techniques for the mining of rock [1].

\section{Research Methods}

Many systematic approaches are used to evaluate and determine the environmental performances of different excavation techniques and procedures. Therefore, an explanation of the procedure which headed to assess the different types of mining equipment by captivating into account many features is presented. Two different models for the evaluation are proposed, where they are Analyses Hierarchical Process (AHP) and Principal Component Analyses (PCA) $[11,13,14]$. These methods are numerically processed using statistical analyses of fuzzy technique.

\section{Setting up the statistical Fuzzy AHP model}

The AHP assessment is largely depending on many points of views, which are technical, environmental, and economic impacts. Each aspect has many evaluation indices as reported in [21,22]. In the AHP model, the evaluation of the mining equipment techniques is the main objective. There are many factors affecting on the criterion level quality, which will be illustrated as follows:

$\mathrm{U}_{1}$ technical aspects $\left(\mathrm{U}_{11}, \mathrm{U}_{12}, \mathrm{U}_{13} \ldots\right.$ etc. $)$

$U_{2}$ Environmental aspects $\left(U_{21}, U_{22}, U_{23} \ldots\right.$ etc. $)$

$U_{3}$ Economic aspects $\left(U_{31}, U_{32}, U_{33} \ldots\right.$ etc. $)$

The relation between the main evaluation of the mining equipment techniques, $U$, and this aspect with all indicators are simplified at Figure (2) [11,21]. The main target of this model is to evaluate the mining equipment techniques $U$, considering the main factors affecting on it, technical $U_{1}$, Environmental $U_{2}$ and economical aspects $U_{3}$. These aspects include thirteen factors each of them has a different weight and effect on the final selection of the technique.

\section{Fuzzy assessment matrix}

Fuzzy assessment matrix represents the connection between the aspect $U_{i m},(i=1,2,3$ and $m$ $=1,2, \ldots$ etc.) and the assessment amount $r_{\text {imj }}$. The total valuation matrix $R_{i}$, for separately assessment item is determined by:

$$
R_{i}=\left[\begin{array}{cccc}
r_{i 11} & r_{i 12} & \cdots & r_{i 1 n} \\
r_{i 21} & r_{i 22} & \cdots & r_{i 2 n} \\
\vdots & \vdots & \vdots & \vdots \\
r_{i m 1} & r_{i m 2} & \cdots & r_{i m n}
\end{array}\right]
$$




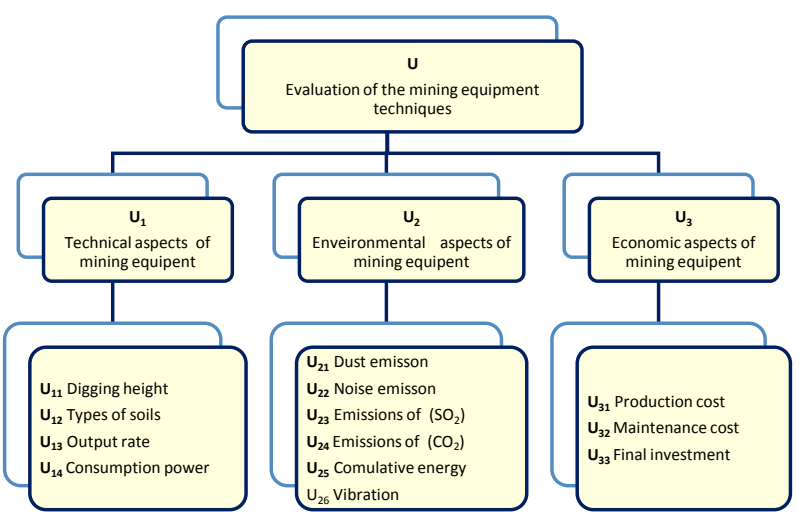

Figure 2 The indicator system for evaluation of mining equipment.

where, $\mathrm{n}$ is number of evaluation factors discussed as follows. Each evaluation factor has its own characteristics or extensity, and has its own dimension and distribution, so there is no way to directly compare or operate. As results, ranging transformation should be applied to the original data to convert it to dimensionless. Additionally, assessment factors may be positive or negative to this assessment; Therefore, the following tasks must be used in case of positive signs [23].

$$
\begin{aligned}
& r_{i m 1}=\left\{\begin{array}{cc}
0 & u<a_{1} \\
\left(u-a_{1}\right) / a_{2} & a_{1} \leq u<a_{2} \\
1 & u \geq a_{2}
\end{array}\right. \\
& r_{i m 2}=\left\{\begin{array}{cc}
u<a_{1} \\
0 & a_{1} \leq u<a_{2} \\
\left(u-a_{1}\right) /\left(a_{2}-a_{1}\right) & u \geq a_{2} \\
0.4 & u<a_{1} \\
0.4 & a_{1} \leq u<a_{2}
\end{array}\right. \\
& r_{i m 3}=\left\{\begin{array}{cc}
u \geq a_{2} \\
\left(a_{2}-u\right) /\left(a_{2}-a_{1}\right) \\
0 & u<a_{1} \\
1 & a_{1} \leq u<a_{2}
\end{array}\right. \\
& r_{i m 4}=\left\{\begin{array}{cc}
u \geq a_{2} \\
\left(a_{2}-u\right) / a_{2}
\end{array}\right.
\end{aligned}
$$

where, $u$ is the equipment criterion, and $a_{1}$ and $a_{2}$ are boundary limits of each criterion. As the Also, the following equations are used in case of negative sign.

$$
\begin{gathered}
r_{i m 1}=\left\{\begin{array}{cc}
1 & u<a_{1} \\
\left(a_{2}-u\right) / a_{2} & a_{1} \leq u<a_{2} \\
0 & u \geq a_{2}
\end{array}\right. \\
r_{i m 2}=\left\{\begin{array}{cc}
u<a_{1} \\
\left(a_{2}-u\right) /\left(a_{2}-a_{1}\right) & a_{1} \leq u<a_{2} \\
0 & u \geq a_{2}
\end{array}\right. \\
r_{i m 3}=\left\{\begin{array}{cc}
u<a_{1} \\
\left(u-a_{1}\right) /\left(a_{2}-a_{1}\right) & a_{1} \leq u<a_{2} \\
0.4 & u \geq a_{2} \\
0 & u<a_{1}
\end{array}\right. \\
r_{i m 4}=\left\{\begin{array}{cc}
a_{1} & \leq u<a_{2} \\
\left(u-a_{1}\right) / a_{2} & u \geq a_{2} \\
1 &
\end{array}\right.
\end{gathered}
$$

\section{Applying Analytic Hierarchy Process (AHP) technique to Determine the weighting factor $(w)$}

Each factor has its own weight and its own effect in the evaluated aspect. Accordingly, the weights are often have pretty unlike deductions in the calculation. This is extremely important part and it has a main influence on the assessment effect in the theory of Fuzzy evaluation. The willpower of the weights straight touches the strength of the assessment model [24]. Generally, the weight of the factors is evaluated by field experiences and some subjective assessment which may has strong personal features.
Unfortunately, these methods occasionally cause incorrect outcomes valuation, because its accuracy depends only on individual experiences. So that, subjective assessment is often implemented by introducing Delphi method in decisive the weights. This technique also shows faintness, and the outcomes are Inopportunely in mining applications [25]. Accordingly, further modeling methods are studied and evaluated for the assessments in mining fields.

The Analytic Hierarchy Process (AHP) method was developed by Saaty 1973 [26]. The AHP is extremely used in the weighting evaluation at the launch of the modeling practice. It is an easy numerical precise technique that suggestions a non-quantitative verdict problem. It is correspondingly a technique, by which particular calculations are accurately implemented. Wherever, in this technique has a part of prejudice, the calculated weights are enhanced by the rational numerical calculation. So that the effect of the subjective factors would be eliminated as possible [23]. In addition, precision of the calculation is enhanced to a great degree by avoiding misperception and errors caused by the coincident calculation of the weights for a huge numeral of signs $[18,20]$. Thus, the AHP method is applied in this study to evaluate the weightings of all assessment indicators as exposed below.

Firstly, in the AHP-based modeling, the objective and the groups of the assessment aspects must be design. Then these aspects are built up into a clear hierarchical structure, which represent the most important step for the AHP method submission as shown in Figure $(2)[11,23]$. Then in the next stage, the matrix of the pair wise judgement calculation is molded. The matrix of comparative assessment is constructed by comparing the elements for each hierarchy level pair wise after setting the hierarchical analysis structure. The AHP-Method is relay on the evaluation of the comparative status of a factor over the others for each level $[21,22]$.

The assessment occurs by comparing between a paired of all factors in each hierarchical step, in which two essentials of a level are assessed with deference to the factor on the upper level of the hierarchy. By applying a suitable gauge, this assessment is estimated in numerical values to construct the evaluation matrix $[11,25] . \mathrm{Ck}$, is an element on a higher level of the hierarchy, it contains elements $A_{1}$, $A_{2} \quad \ldots \quad A_{m}$ above the lesser hierarchy level. The assessment matrix illustrated below shows a pair evaluation of the elements $A_{1}, A_{2} \ldots A_{m}$.

$$
\begin{aligned}
& \begin{array}{llllll}
C_{k} & A_{1} & A_{2} & \ldots \ldots & A_{m}
\end{array} \\
& \begin{array}{lllll}
A_{1} & a_{11} & a_{i 2} & \ldots \ldots & a_{1 m}
\end{array} \\
& \begin{array}{lllll}
A_{2} & a_{21} & a_{22} & \ldots . . & a_{2 m}
\end{array} \\
& \begin{array}{lllll}
\ldots \ldots . & \ldots \ldots . & \ldots . & \ldots . . & \ldots . . \\
A_{m} & a_{m 1} & a_{m 2} & \ldots \ldots . & a_{m m}
\end{array} \\
& A=\left[\begin{array}{cccc}
a_{11} & a_{12} & \cdots & a_{1 m} \\
a_{21} & a_{22} & \cdots & a_{2 m} \\
\cdots & \cdots & \cdots & \cdots \\
a_{m 1} & a_{m 2} & \cdots & a_{m m}
\end{array}\right]
\end{aligned}
$$

where $a_{i j}$ is strength of the significance of the element Ai Vs. the element $\mathrm{Aj}$. The matrix $\mathrm{A}$ has the following features:

$$
a_{i j}>0, a_{i j}=1 / a_{j i}(i \neq j),
$$




$$
a_{i i}=1 \quad(i=1,2, \ldots, m)
$$

Generally, the matrix is referred with the above possessions, as a sign (+ or - ) matrix. If aij $\times$ ajp = aip is usable for all $i, j$ and $p$, this sign (positive and negative) matrix is steady and Vice versa. The matrix $A$, in real, is not usually has a complete steadiness. Consequently, the steadiness of the assessment matrix must be reached $[14,16]$.

To construct matrix $A$, the pair judgements are signified by the numbers that express the comparative status of a factor. In AHP method, it is suggested to use the essential scale for matching judgement which ranged from 1 to 9 for the properly humanoid skill to distinguish (see Table (1)). The self-comparison of an element, $\mathrm{A} 1$ and $\mathrm{A} 1$ for instance, consequences in a charge of 1 , consequently; all diagonal items of the matrix of are ones $[14,16]$.

Table 1 Comparison scale for the AHP Method [27].

\begin{tabular}{|c|c|}
\hline Score $\mathrm{a}_{\mathrm{ij}}$ & Comparison index \\
\hline 1 & Equal importance \\
\hline 3 & Moderately important \\
\hline 5 & Greater significance \\
\hline 7 & Strongly important \\
\hline 9 & Extremely high important \\
\hline $2,4,6,8$ & Intermediate values between all above \\
\hline
\end{tabular}

Third step, the ranking position will be estimated. To adjust the ranking of status of the assessment aspects, the comparative status of each aspect of a definite classified level must be estimated regard to an associate of the upper hierarchy level. So that, the assessment matrix is constructed by calculating the maximum eigenvalues and the eigenvector. This eigenvector represents the status ranking and the weight vector of assessment aspects. Therefore, a weighting of the assessment factors is determined rendering to their worth [26]. The eigenvector of the assessment matrix, can be evaluated according to the following procedure:

$$
M_{i}=\prod_{j=1}^{m} a_{i j}, \quad i=1,2, \ldots, m
$$

where $\mathrm{Mi}$ is the item of each row of the assessment matrix, $M$,

Then, $\overline{W_{l}}$, which is the root of $\mathrm{Mi}$, is calculated by:

$$
\overline{W_{i}}=\sqrt[m]{M_{i}}
$$

Then, the weights can be carried out by:

$$
\begin{aligned}
& \bar{W}=\left[\overline{W_{1}}, \overline{W_{2}}, \ldots \ldots, \overline{W_{m}}\right]^{T} \\
& W_{i}=\overline{W_{i}} /\left(\sum_{j=1}^{m} \overline{W_{j}}\right)
\end{aligned}
$$

Finally, the vector $W_{i}=\left[W_{1}, W_{2} \ldots \ldots, W_{m}\right]^{T}$ are valid for the eigenvector and the weight vector. Built on the matching pair-wise judgment matrix of A-B level, components in equal of the hierarchy were likened to single component at the level right above and graded by eigenvector of the matrix [27]. The eigenvalues of $\lambda$ max is calculated as follows:

$$
\lambda_{\text {max }}=\sum_{i=1}^{m} \frac{(A W)_{i}}{m W_{i}}
$$

$A W=\left[\begin{array}{cccc}a_{11} & a_{12} & \cdots & a_{1 m} \\ a_{21} & a_{22} & \cdots & a_{2 m} \\ \cdots & \cdots & \cdots & \cdots \\ a_{m 1} & a_{m 2} & \cdots & a_{m m}\end{array}\right] \times\left[\begin{array}{c}W_{1} \\ W_{2} \\ \vdots \\ W_{j}\end{array}\right]$

Where $W$ is the matching eigenvector of $\lambda$ max and $W i$ $(i=1,2 \ldots n)$ is the ranking weight value. In the final step, the reliability of the assessment matrix is inspected. The eigenvector achieved in the latest stage is the weighting vector. The weight distribution relies on the reliability approval of the assessment matrix. The reliability of the assessment matrix must be inspected as following formula: $[16,24,27]$.

$$
\begin{aligned}
& C I=\frac{1}{n-1}\left(\lambda_{\max }-n\right) \\
& C R=C I / R I
\end{aligned}
$$

Where $\mathrm{Cl}$ is the Consistency Index (Consistency) and $C R$ is the Consistency Ratio. When $\lambda$ max value becomes closer to $n$, the consistency of the assessment matrix and RI (Random Consistency Index) becomes higher. RI index is shown in Table (2).

Table 2 Random Consistency Index (RI) and consistency ratio evaluation [27].

\begin{tabular}{|c|c|c|c|c|c|c|c|c|c|}
\hline $\begin{array}{c}\text { Order } \\
(\mathrm{n})\end{array}$ & 1 & 2 & 3 & 4 & 5 & 6 & 7 & 8 & 9 \\
\hline$(\mathrm{RI})$ & 0.0 & 0.0 & 0.58 & 0.90 & 1.12 & 1.24 & 1.32 & 1.41 & 1.45 \\
\hline
\end{tabular}

The consistency ratio is acceptable when it values less than or equal $10 \%(C R \leq 0.1)$, and then the assessment matrix is consistency satisfied, and the weight sharing is realistic, otherwise it is desirable to repeat the calculation for the pair comparison matrix to enhance the $\mathrm{CR}$.

\section{Fuzzy model assessment}

Afterward building of the assessment matrix of the Fuzzy assessment and specifying the weighting of the assessment parameters and indicators in terms of their significance, the typical of the Fuzzy assessment would be defined as follows:

$$
\begin{gathered}
B_{i}=W_{i} \times R_{i}=\left(b_{i 1}, b_{i 2}, b_{i 3}, b_{i 4}\right) \\
(i=1,2, \ldots, 4)
\end{gathered}
$$

If $\sum b_{i j} \neq 1$, then $\mathrm{Bi}$ should be normalized by:

$$
\begin{aligned}
& \dot{b}_{\imath \jmath}=b_{i j} / \sum_{k=1}^{4} b_{i k} \quad, j=(1,2, \ldots, 4) \\
& R=\left[\begin{array}{l}
B_{1} \\
B_{2} \\
B_{3} \\
B_{4}
\end{array}\right]
\end{aligned}
$$

If $\sum b_{j} \neq 1$, then $\mathrm{B}$ should be normalized by:

$$
B=W \times R=\left(b_{1}, b_{2}, b_{3}, b_{4}\right)
$$

The evaluation result $b_{j}$ shows the category, how extreme the evaluation item to the calculation class is weighed. The calculation class, in harmony with the value of supreme relationship was definite, also the assessment class concerning the maximum assessment relationship bj, as the assessment result necessity be chosen $[21,25]$.

\section{Principal Component Analysis (PCA) evaluation model}

In the evaluation system, it is problematic to evaluate the entire level for the aspects, which affect the process procedures. The primary element analysis primarily involves an orthogonal conversion of main factors into a group of new uncorrelated factors, 
called principal components (PC). These are linear arrangements of main factors, where the mathematician efforts, with as limited main elements, to replicate the difference of the main factors. The main resolve of the principal component's examination is the statistics saving $[28,29]$. Generally, the main mechanisms have the subsequent relations to the main factors, and the calculation of PCA follows these steps:

\section{Step 1: Treatment for the assessment indicators}

Some evaluations have negative gages of the improvement. In order to shorten the evaluation analysis, it is essential to change them into positive gages. The value of the main indicators is swapped by mutual standards of the displays. If the worth of assessment indicators and of tester data is set, the matrix of the main data will be calculated as follows:

$$
X=\left[\begin{array}{cccc}
x_{11} & x_{12} & \cdots & x_{1 p} \\
x_{21} & x_{22} & \cdots & x_{2 p} \\
\cdots & \cdots & \cdots & \ldots \\
x_{n 1} & x_{n 2} & \cdots & x_{n p}
\end{array}\right]
$$

\section{Step 2: Adjustment action of the main data}

To reduce the variance in measurement among the elements, the original date must be standardized by:

$$
\dot{x}_{i j}=\frac{x_{i j}-\bar{x}_{j}}{\sigma_{j}}(i=1,2, \ldots, n ; j=1,2, \ldots, p)
$$

where $\bar{x}_{j}$ and $\sigma_{\mathrm{j}}$ are, the mean and standard deviation of the variables in the column respectively and calculated by:

$$
\bar{x}_{j}=\frac{1}{n} \sum_{i=1}^{n} x_{i j},, \quad \sigma_{j}=\sqrt{\frac{1}{n-1} \sum_{i=1}^{n}\left(x_{i j}-\bar{x}_{j}\right)^{2}}
$$

Step 3: The correlation matrix $R$ of the standardized data

The correlation matrix $\mathrm{R}$ of the standardized data is constructed by:

$$
R=\left[\begin{array}{llll}
r_{11} & r_{i 12} & \cdots & r_{1 p} \\
r_{21} & r_{i 22} & \cdots & r_{2 p} \\
\cdots & \cdots & \cdots & \cdots \\
r_{p 1} & r_{p 2} & \cdots & r_{p p}
\end{array}\right]
$$

To abridge the estimation, the identical data of the main data is signified by $X$. The correlation factors of the identical data, which is the essentials of the matrix $R$ are evaluated by:

$$
r_{i j}=\frac{1}{n-1} \sum_{t=1}^{n} x_{t i} x_{t j} \quad(i, j=1,2, \ldots, p)
$$

Step 4: Eigenvalues and eigenvectors of the correlation matrix $\mathbf{R}$

The following characteristic polynomial represents the first step in the calculation of the eigenvectors from the eigenvalues of the correlation matrix $R$

$$
|R-\lambda I|=0
$$

where $I$ is the identity matrix and $\lambda$ is the eigenvalues. $R$ has a number $p$ of eigenvalues $\lambda_{1}, \lambda_{2}, \ldots \lambda_{p}$. They are all have a different value, indexed and arranged in descending order and are ordered, as $\mathrm{R}$ is a symmetric matrix.

The eigenvectors of $\mathrm{R}$ are calculated from the following formulation:

$$
(R-\lambda I) c=0
$$

The sought vectors (c), which represent the eigenvectors of the matrix $R$ of the eigenvalues $\lambda$, will be calculated as follows:

$$
c_{j}=\left(c_{j 1}, c_{j 2}, \ldots, c_{j p}\right)^{\prime},(j=1,2, \ldots, p)
$$

Then new variables can be obtained as follows:

$$
\left\{\begin{array}{c}
y_{1}=c_{11} x_{1}+c_{12} x_{2}+\cdots+c_{1 p} x_{p} \\
y_{2}=c_{21} x_{1}+c_{22} x_{2}+\cdots+c_{2 p} x_{p} \\
\cdots=\cdots \cdots \cdots \\
y_{p}=c_{p 1} x_{1}+c_{p 2} x_{2}+\cdots+c_{p p} x_{p}
\end{array}\right.
$$

The new variables (PC) $\mathrm{y}_{1}, \mathrm{y}_{2}, \ldots \mathrm{y}_{\mathrm{p}}$, are linear mixtures of the main variables $[28,29]$. Which are estimated consecutively, according to their effect, i. e. the primary PC has a major part of the entire deviation, then the following PC has the succeeding prime part, etc.

Step 5: Calculation of the effect percentage of the variance of all PC

The part of the variance $a_{j}$ of the PC $y_{j}$ is calculated as follows:

$$
a_{j}=\lambda_{j}\left(\sum_{i=1}^{p} \lambda_{i}\right)^{-1}
$$

The buildup share of variance of the PC is calculated by the following formula:

$$
\sum_{j=1}^{m} a_{j}=\sum_{j=1}^{m} \lambda_{j}\left(\sum_{i=1}^{p} \lambda_{i}\right)^{-1}(m=1,2, \ldots, p)
$$

\section{Step 6: PC Selection}

The impartial of PC is to create, from a particular amount of very correlated variables $x_{1}, x_{2}, \ldots, x_{p}, a$ lesser number of new variables $y_{1}, y_{2}, \ldots y_{m} \quad(m<p)$, as direct mixtures. Generally, the buildup portion of adjustment percentage of the $m$ designated of the PC should surpass $85 \%$.

$$
\sum_{j=1}^{m} a_{j}=\sum_{j=1}^{m} \lambda_{j}\left(\sum_{i=1}^{p} \lambda_{i}\right)^{-1} \quad \geq 85 \%
$$

Step 7: The designated PC and the entire assessment values

Values of the entire selected PC will be obtained if the regular data, in the formula (34), are used. Then the evaluation rate $(F)$ of the evaluated element results from:

$$
F=\sum_{j=1}^{m} a_{j} y_{j}
$$

F value is directly proportional with the level of progress of the assessment item. Then, the statuses of economic development $F_{1}$, social development $F_{2}$, environmental capacity $F_{3}$ and sustainability of the resources $\mathrm{F} 4$, will be estimated. The total standard of progress is given by:

$$
F^{*}=\sum_{i=1}^{4} W_{i} F_{i}
$$

where $W_{i}$ is the weight of $F_{i}$.

\section{Research Methodology and the proposed model}

In this paper, the comparison between the seven types of the technical equipment for surface mining is accomplished. Accordingly, the best method to replace the drilling and blasting method is ascertained. To accomplish this task, the following procedure is done. 
a. The field and technical data are collected either from the field or from the literature.

b. Applying AHP method using the collected data and solve the system using Fuzzy logic.

c. The above step is rapidity done for each method of the seven extraction techniques, individually.

d. Repeat steps b and c for the applications of the PCA method.

e. Evaluate the results and compare the performance.

The investigation was based on the experiences and the inspections of surface mines for solid rock as well as on analyses made at the Technical University Mining Academy Freiberg Germany (TU Bergakademie Freiberg) [1-3]. These data are mainly technical, environmental, and economical aspects. Most of the technical characteristics (Digging height, Types of soils, Output rate, Maintains and repair cost, and Final investments) are collected from the technical reports and operating catalogs for each method. The rest of the records are taken from published data $[1,10]$, and the assessment of the estimation indicators for types of features are illustrated in Tables (3) and (4).

\section{Results and discussions}

In this section, the AHP and PCA presented in section 2 are used to assess the various surface mining techniques. This assessment is objectively studied to ascertain alternative options instead of the ordinary drilling and blasting method. this is to avoid the corresponding challenges in the field. The models AHP and PCA are applied to the seven well-known techniques utilized in the surface mining as summarized in Table (3) as evaluated as follows.

\section{Calculation of the AHP method}

The weighting of all indicators was calculated according to Tables (1) and (2) and the formulas from (10) to (18) as shown in Tables (5). After calculating the weightages and the Fuzzy assessment matrices, the control gates by means of the formulas (18) to (22). The results of evaluation of the equipment according to the principle of maximum connection are illustrated in Table (6) [30].

As shown in Figures (3) and (4), the drilling and blasting is the best way to break rocks then bucket wheel excavator, hydraulic excavator, surface miner, hydraulic hammer, bulldozer, and face miner, respectively. The characteristics aspect used as general criteria for choosing, at the first step of evaluation, the bucket wheel excavator is the most efficient equipment that could be used in an order after drilling and blasting method. Under certain circumstances, it is false such as the diggings procedure may be a quite difficult in the case of hard rock [28-30]. For the hard rock case, the choice is changed to find another appropriate type, so that the hydraulic excavator who comes in the third place of the evaluation process could be the suitable select to do this task $[19,21,29]$. Hydraulic hammers and bulldozers are very close in their rank, but hydraulic hammer excels in technical and environmental characteristics giving it a fifth place ahead of the bulldozer. Finally, the overall evaluation for the three aspects is illustrated in Figure (4) which gives the results of AHP [11,19,20,30].

Table 3 The real standards of indicators for different techniques reported in $[1,11]$.

\begin{tabular}{|c|c|c|c|c|c|c|c|}
\hline \multirow[b]{2}{*}{ Criteria } & \multicolumn{7}{|c|}{ Types of equipment } \\
\hline & 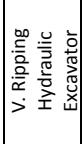 & 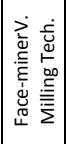 & 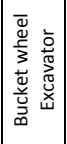 & 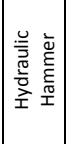 & 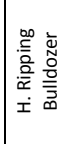 & 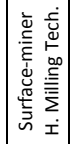 & 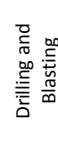 \\
\hline \multicolumn{8}{|c|}{ 1- Technical of equipment aspects } \\
\hline $\mathrm{U}_{11}$ Digging height $(\mathrm{m})$ & 12 & 13 & $20-50$ & 10 & $2-4$ & 9 & $>50$ \\
\hline $\mathrm{U}_{12}$ Types of soils $\sigma$ (Mpa) & 35 & 50 & 50 & 200 & 120 & $50-100$ & $>250$ \\
\hline $\mathrm{U}_{13}$ Output rate $(1000 \mathrm{~m} 3 / \mathrm{hr})$ & 0.5 & 2 & 20 & 0.4 & 0.2 & 3 & $>20$ \\
\hline $\mathrm{U}_{14}$ Consumption power $(1000 \mathrm{~kW})$ & 4 & 6 & 8 & 12 & 5 & 3 & $<2$ \\
\hline \multicolumn{8}{|c|}{ 2- Enveironmental aspects } \\
\hline $\mathrm{U}_{21}$ Dust emisson. $(\mathrm{g} / \mathrm{t})$ & 160 & 900 & 400 & 205 & 370 & 190 & 120 \\
\hline $\mathrm{U}_{22}$ Noise $(\mathrm{dB})$ & 103 & 114 & 108 & 114 & 113 & 114 & 113 \\
\hline $\mathrm{U}_{23}$ Emissions of $\mathrm{SO} 2$ (g/t rock) & 9.2 & 8.9 & 1.4 & 15.4 & 13.5 & 15.1 & 8 \\
\hline $\mathrm{U}_{24}$ Emissions of $\mathrm{CO} 2$ (g/t rock) & 993 & 2178 & 505 & 1647 & 1450 & 1598 & 948 \\
\hline $\mathrm{U}_{25}$ Cumulative Energ (Mj/t rock) & 13 & 33 & 13 & 22 & 18.9 & 20.8 & 9.8 \\
\hline $\mathrm{U}_{26}$ Vibration (\%) & 40 & 50 & 40 & 75 & 50 & 50 & 80 \\
\hline \multicolumn{8}{|c|}{ 3- Economic aspects } \\
\hline $\mathrm{U}_{31}$ production cost $(\%)$ & 48 & 100 & 60 & 70 & 72 & 80 & 50 \\
\hline $\mathrm{U}_{32}$ Maintains and repair cost (\%) & 80 & 90 & 45 & 80 & 50 & 60 & 30 \\
\hline$U_{33}$ Final investments (\%) & 80 & 70 & 90 & 70 & 70 & 65 & 100 \\
\hline
\end{tabular}

Table 4:The arrangement evaluation of the assessment indicators for different types of aspects reported in [11].

\begin{tabular}{|c|c|c|c|c|c|}
\hline & \multicolumn{5}{|c|}{ Rating Classifications } \\
\hline & High & $\begin{array}{c}\text { Relativel } \\
\mathrm{y} \text { high }\end{array}$ & Medium & & Low \\
\hline \multicolumn{6}{|c|}{ 1- Technical of equipment aspects } \\
\hline $\mathrm{U}_{11}$ Digging height $(\mathrm{m})$ & 20 & $10-20$ & 5-10 & $<$ & 5 \\
\hline $\mathrm{U}_{12}$ Types of soils $\sigma(\mathrm{Mpa})$ & 100 & $50-100$ & $25-50$ & $<$ & 25 \\
\hline $\mathrm{U}_{13}$ Output rate $(1000 \mathrm{~m} 3 / \mathrm{hr})$ & 15 & 5-15 & $2-5$ & $<$ & 2 \\
\hline $\mathrm{U}_{14}$ Consumption power $(1000 \mathrm{~kW})$ & 10 & $5-10$ & $2-5$ & $<$ & 2 \\
\hline \multicolumn{6}{|c|}{ 2- Enveironmental aspects } \\
\hline $\mathrm{U}_{21}$ Dust emisson. $(\mathrm{g} / \mathrm{t})$ & 1000 & $500-1000$ & $200-500$ & $<$ & 200 \\
\hline $\mathrm{U}_{22}$ Noise $(\mathrm{dB})$ & 110 & $80-110$ & $50-80$ & $<$ & 50 \\
\hline $\mathrm{U}_{23}$ Emissions of $\mathrm{SO} 2$ (g/t rock) & 12 & 6-12 & $2-6$ & $<$ & 2 \\
\hline $\mathrm{U}_{24}$ Emissions of $\mathrm{CO} 2 \quad(\mathrm{~g} / \mathrm{t}$ rock) & 2000 & $1000-2000$ & $500-1000$ & $<$ & 500 \\
\hline $\mathrm{U}_{25}$ Cumulative Energ (Mj/t rock) & 30 & $20-30$ & $10-20$ & $<$ & 10 \\
\hline $\mathrm{U}_{26}$ Vibration (\%) & 75 & $40-75$ & $10-40$ & $<$ & 10 \\
\hline \multicolumn{6}{|c|}{ 3- Economic aspects } \\
\hline $\mathrm{U}_{31}$ production cost $(\%)$ & 80 & $50-80$ & $20-50$ & $<$ & 20 \\
\hline $\mathrm{U}_{32}$ Maintains and repair cost (\%) & 50 & $20-50$ & $10-20$ & $<$ & 10 \\
\hline $\mathrm{U}_{33}$ Final investments (\%) & 80 & $50-80$ & $30-50$ & $<$ & 30 \\
\hline
\end{tabular}

Technical specification has the largest effect on the evaluation of the surface mining techniques. Drilling and blasting technique has the wider technical specification then bucket wheel excavator, while 
horizontal excavator is the last one in this category. Drilling and blasting, bucket wheel excavator, and horizontal excavator almost have the same environmental evaluation effect, the highest, which is the main reason to raise the horizontal excavator to the third category in the overall evaluation after drilling and blasting and bucket wheel excavator and before Surface-miner. Hydraulic hammer and horizontal ripping bulldozer are nearly equal in their weight and effect and in their overall evaluation. Faceminer comes at the end of this classification that is because it has the lowest technical, and environmental aspects among all studied techniques.

Table $\mathbf{0}$ Weightages of all indicators on the hierarchy level of the criterion.

\begin{tabular}{|c|c|c|c|c|c|}
\hline \multicolumn{3}{|c|}{ Weight of all aspects } & \multicolumn{3}{|c|}{ Weight of technical aspects } \\
\hline $\mathrm{u}$ & w & $\begin{array}{l}\text { Check the } \\
\text { Consistency }\end{array}$ & $\mathrm{U}_{1}$ & w & $\begin{array}{l}\text { Check the } \\
\text { Consistency }\end{array}$ \\
\hline $\begin{array}{l}\mathrm{U}_{1} \\
\mathrm{U}_{2} \\
\mathrm{U}_{3}\end{array}$ & $\begin{array}{l}0.121929 \\
0.319728 \\
0.558343\end{array}$ & 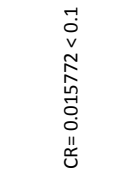 & $\begin{array}{l}\mathrm{U}_{11} \\
\mathrm{U}_{12} \\
\mathrm{U}_{13} \\
\mathrm{U}_{14}\end{array}$ & $\begin{array}{c}0.307312 \\
0.16967 \\
0.432368 \\
0.09065\end{array}$ & 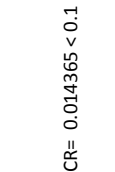 \\
\hline \multicolumn{3}{|c|}{ Weight of environmental aspects } & \multicolumn{3}{|c|}{ Weightages of economic aspects } \\
\hline $\mathrm{U}_{2}$ & w & $\begin{array}{l}\text { Check the } \\
\text { Consistency }\end{array}$ & $\mathrm{U}_{3}$ & w & $\begin{array}{l}\text { Check the } \\
\text { Consistency }\end{array}$ \\
\hline $\begin{array}{l}U_{21} \\
U_{22} \\
U_{23} \\
U_{24} \\
U_{25} \\
U_{26}\end{array}$ & $\begin{array}{c}0.329947 \\
0.053173 \\
0.127626 \\
0.221101 \\
0.17553 \\
0.092622\end{array}$ & 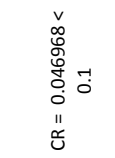 & $\begin{array}{l}U_{31} \\
U_{32} \\
U_{33}\end{array}$ & $\begin{array}{l}0.194614 \\
0.537377 \\
0.268009\end{array}$ & 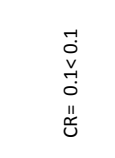 \\
\hline
\end{tabular}

\section{Calculation of the PCA method}

Many mathematical designs are involved in this technique such as adjustment of the pointer data, the correlation matrix, and the eigenvalues and eigenvectors of the correlation matrix to excellent the principal components [28-30]. The final evaluation results of all systems are shown in Table (7) and in Figures (5) and (6).

The evaluation and the weight of each aspect in this method differ from that in the AHP method. For example, the value of the technical aspect in the AHP method for the bucket while excavator is comparatively high, and its economical aspect is low Figure (3). However, this value is relatively converted, where the economical aspect is high, and its technical aspect is low as shown in Figure (5). This situation is corrected by using different weights for each aspect. As shown in Figure (6) the final evaluation order is that drilling and blasting have the highest evaluation rate then bucket wheel excavator, hydraulic excavator, surface miner, hydraulic hammer, bulldozer, and faceminer, respectively. The conclusion attained by these results of applying the PCA method is almost matched with the previous method AHP of calculations.
Table 6: Calculation of the AHP evaluation method.

\begin{tabular}{|c|c|c|}
\hline & Technical aspects & Envi. aspects \\
\hline $\begin{array}{l}\text { Hydraulic Excavator } \\
\text { (H.Ex) }\end{array}$ & $\left(\begin{array}{llll}0.18 & 0.235 & 0.51 & 0.68\end{array}\right)$ & $\left(\begin{array}{llll}0.617 & 0.52 & 0.28 & 0.2\end{array}\right)$ \\
\hline $\begin{array}{l}\text { Face-miner } \\
\text { (F.M) }\end{array}$ & $\left(\begin{array}{llll}0.19 & 0.25 & 0.75 & 0.62\end{array}\right)$ & $\left(\begin{array}{llll}0.1 & 0.12 & 0.614 & 0.8\end{array}\right)$ \\
\hline $\begin{array}{c}\text { Bucket wheel } \\
\text { Excavator (BWE) }\end{array}$ & $\left(\begin{array}{llll}0.8 & 0.374 & 0.18 & 0.14\end{array}\right)$ & $\left(\begin{array}{llll}0.64 & 0.72 & 0.17 & 0.17\end{array}\right)$ \\
\hline $\begin{array}{l}\text { Hydraulic Hammer } \\
(\mathrm{H} ; \mathrm{Ha})\end{array}$ & $\left(\begin{array}{llll}0.25 & 0.17 & 0.31 & 0.6\end{array}\right)$ & $\left(\begin{array}{llll}0.351 & 0.45 & 0.38 & 0.47\end{array}\right)$ \\
\hline $\begin{array}{l}\text { Horizontal Ripping } \\
\text { Bulldozer (Bul) }\end{array}$ & $\left(\begin{array}{llll}0.22 & 0.13 & 0.33 & 0.8\end{array}\right)$ & $\left(\begin{array}{llll}0.37 & 0.48 & 0.42 & 0.45\end{array}\right)$ \\
\hline $\begin{array}{c}\text { Surface-miner } \\
\text { (S:M) }\end{array}$ & $\left(\begin{array}{llll}0.32 & 0.26 & 0.63 & 0.54\end{array}\right)$ & $\left(\begin{array}{llll}0.46 & 0.3 & 0.39 & 0.42\end{array}\right)$ \\
\hline \multirow[t]{2}{*}{$\begin{array}{l}\text { Drilling and Blasting } \\
\text { (D\&B) }\end{array}$} & $\left(\begin{array}{llll}0.999 & 0.399 & 0 & 0\end{array}\right)$ & $\left(\begin{array}{llll}0.66 & 0.41 & 0.2 & 0.26\end{array}\right)$ \\
\hline & Economic aspects & All aspects \\
\hline $\begin{array}{l}\text { Hydraulic Excavator } \\
\text { (H.Ex) }\end{array}$ & $\left(\begin{array}{llll}0.35 & 0.21 & 0.31 & 0.61\end{array}\right)$ & $\left(\begin{array}{llll}0.41 & 0.31 & 0.32 & 0.49\end{array}\right)$ \\
\hline $\begin{array}{l}\text { Face-miner } \\
\text { (F.M) }\end{array}$ & $\left(\begin{array}{llll}0.13 & 0.214 & 0.35 & 0.77\end{array}\right)$ & $\left(\begin{array}{llll}0.13 & 0.19 & 0.48 & 0.76\end{array}\right)$ \\
\hline $\begin{array}{c}\text { Bucket wheel } \\
\text { Excavator (BWE) }\end{array}$ & $\left(\begin{array}{llll}0.37 & 0.24 & 0.6 & 0.47\end{array}\right)$ & $\left(\begin{array}{llll}0.51 & 0.41 & 0.41 & 0.34\end{array}\right)$ \\
\hline $\begin{array}{l}\text { Hydraulic Hammer } \\
(\mathrm{H} ; \mathrm{Ha})\end{array}$ & $\left(\begin{array}{llll}0.06 & 0.1 & 0.59 & 0.79\end{array}\right)$ & $\left(\begin{array}{llll}0.18 & 0.21 & 0.49 & 0.67\end{array}\right)$ \\
\hline $\begin{array}{l}\text { Horizontal Ripping } \\
\text { Bulldozer (Bul) }\end{array}$ & $\left(\begin{array}{llll}0.05 & 0.08 & 0.6 & 0.8\end{array}\right)$ & $\left(\begin{array}{llll}0.175 & 0.211 & 0.51 & 0.68\end{array}\right)$ \\
\hline $\begin{array}{l}\text { Surface-miner } \\
(\mathrm{S}: \mathrm{M})\end{array}$ & $\left(\begin{array}{llll}0.12 & 0.19 & 0.37 & 0.783\end{array}\right)$ & $\left(\begin{array}{llll}0.25 & 0.23 & 0.41 & 0.63\end{array}\right)$ \\
\hline $\begin{array}{l}\text { Drilling and Blasting } \\
\text { (D\&B) }\end{array}$ & $\left(\begin{array}{llll}0.56 & 0.47 & 0.37 & 0.3\end{array}\right)$ & $\left(\begin{array}{llll}0.65 & 0.44 & 0.27 & 0.24\end{array}\right)$ \\
\hline
\end{tabular}

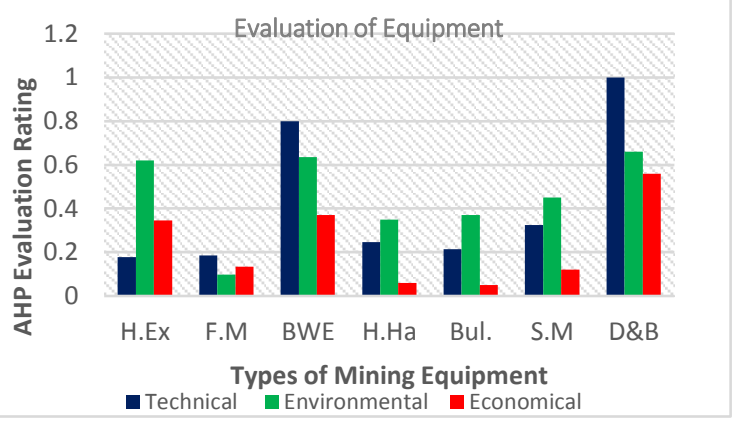

Figure 3 AHP evaluation method for aspects.

\section{All Aspects of Mining Equipment}

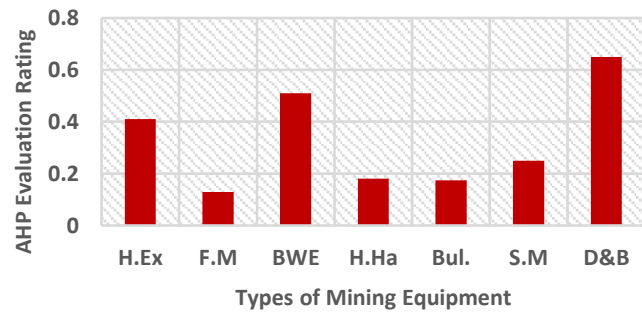

Figure 4 Overall evaluation method of AHP.

Table 7 Calculation of the PCA evaluation method.

\begin{tabular}{|c|c|c|c|c|}
\hline Type of Equpment & $\begin{array}{c}\mathrm{F} \\
\text { char. }\end{array}$ & $\begin{array}{c}F \\
\text { env. }\end{array}$ & $\begin{array}{c}F \\
\text { econ. }\end{array}$ & F.f \\
\hline Hydraulic Excavator (H.Ex) & -0.63 & 0.14 & 0.52 & 0.25 \\
\hline Face-miner (F.M) & -0.51 & -0.1 & -1.4 & -0.86 \\
\hline $\begin{array}{c}\text { Bucket wheel Excavator } \\
\text { (BWE) }\end{array}$ & 0.14 & 0.54 & 0.75 & 0.61 \\
\hline Hydraulic Hammer $(\mathrm{H} ; \mathrm{Ha})$ & 0.15 & -0.1 & -0.42 & -0.25 \\
\hline $\begin{array}{c}\text { Horizontal Ripping } \\
\text { Bulldozer (Bul) }\end{array}$ & -0.17 & -0.45 & -0.22 & -0.29 \\
\hline Surface-miner ( S:M) & -0.18 & -0.55 & -0.69 & -0.58 \\
\hline Drilling and Blasting (D\&B) & 1.19 & 0.48 & 1.46 & 1.12 \\
\hline
\end{tabular}




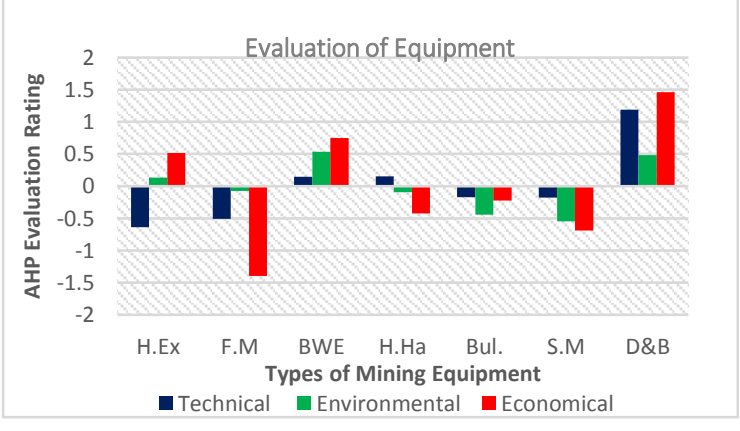

Figure 5 PCA evaluation method for aspects.

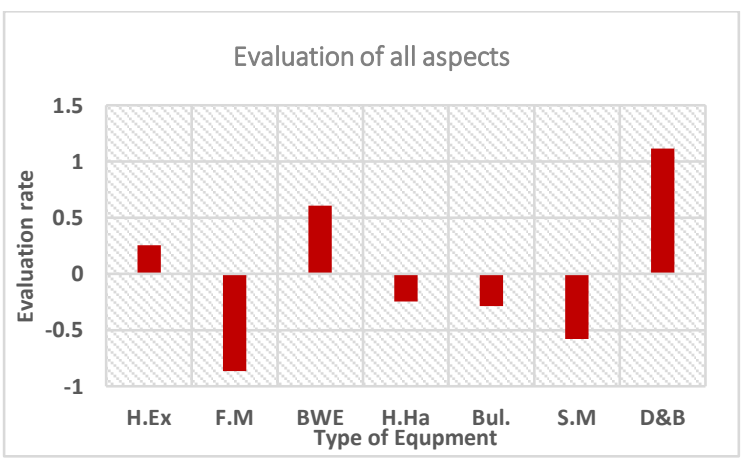

Figure 5 PCA evaluation method of all aspects.

\section{Comparison among the different surface mining techniques}

From the above discussions, the method of drilling and blasting represents the highest efficiency among the methods used in surface mines. Therefore, other techniques are evaluated related to the traditional drilling and blasting technique. The results presented in figure (7) are computed as a percentage to the drilling and blasting rating value. For example, the bucket wheel excavator, the highest adeptness in the order after drilling and blasting, represents around $78.5 \%$. On the other hand, the last one in the order is the Face-miner that represents about $20.0 \%$ from the efficiency of the drilling and blasting procedure. The efficiencies compared to drilling and blasting efficiency of hydraulic excavator, surface miner, hydraulic hammer and bulldozer are around $63.1 \%$, $38.5 \%, 27.7 \%$ and $26.9 \%$, respectively. Hydraulic hammer and bulldozer are very close in their rating and could be considered as equal in this evaluation. Finally, although the most effective method in rock breakage is the drilling and blasting, it can be replaced by the other techniques, however in different percentage efficacy. The closest method to the drilling and blasting is the bucket wheel excavator, while the very fare one is the Face-miner method.

By reviewing and studying the previous works, we find that these works focused on choosing an alternative rock breakage for the drilling and blasting method. The results showed that (BWE) was the best alternative method and the top solution when focusing on environmental and the cost aspects in the individual mining techniques show that the relative differences of a far-away opencast mine are much higher than those of an open-cast mine near a builtup area. figure 8 . By comparing the present work and the previous one illustrated in figure. 8 the similarity will be clarified however, the differences in the parameter. Also, the present work shows that the (BWE) gets the first choice after drilling and blasting operations because of technical parameters added in this work so that the result could be the same $[1,2,3]$. On the other hand, the (FAHP) method was used to choose the most appropriate underground and in open cast mining too for a specific mine and the result was matched with the results obtained from the traditional selection methods $[2,4,11]$. (AHP-PAC) the method was also used in the optimal selection of the locations of the Ore dressing units in the mine site, and therefore it is considered one of the best methods of selection in both surface and subsurface mining operations, which have proven their efficiency and can be relied upon to give good results $[4,20]$.

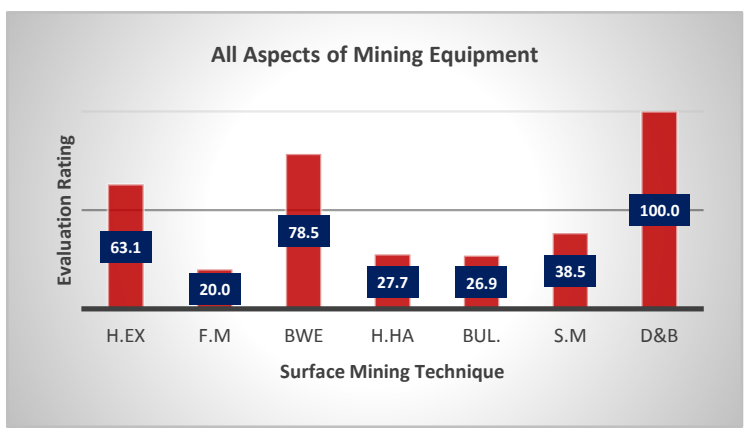

Figure 7 Comparison among different techniques

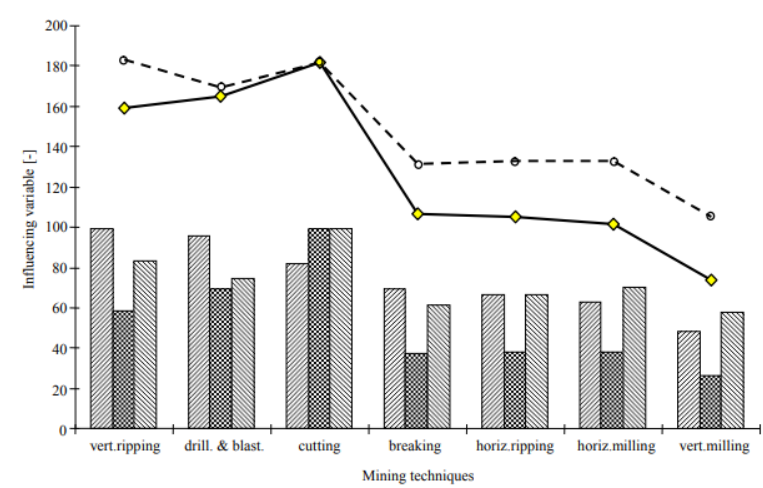

Figure 8: Evaluation of different mining operation using scaling statistical accounting method the environmental and costs effects by Schmieder P. [1]

\section{Conclusions}

This paper presented the assessment of different techniques applied in fracturing rocks in surface mines in accordance with their technical, environmental, and economical aspects. In which, two different procedures of evaluation (Analyses Hierarchical Process (AHP) and Principal Component Analyses (PCA)) were applied to perform the assessment, and they were processed using the statistical analyses of fuzzy methods. Six mining techniques in addition to the drilling and blasting, have been examined about their technical aspects, environmental effects, and production costs. The results of the two mathematical models were very close and proved that the drilling and blasting was the superior method then the order was found as bucket wheel excavator, hydraulic excavator, surface miner, hydraulic hammer, 
bulldozer, and face miner respectively. Hydraulic hammer and bulldozer were very close in their rating and could be considered as equal in this evaluation. The competences compared to drilling and blasting efficiency of bucket wheel excavator, hydraulic excavator, surface miner, hydraulic hammer, bulldozer, and face miner were around $78.5 \%, 63.1 \%$, $38.5 \%, 27.7 \%, 26.9 \%$ and $20 \%$ respectively.

\section{References}

[1] P. Schmieder, and C. Drebenstedt, Anwendung and Weiterentwicklung der methodology der Umweltbilanzierung für den Abbau von Festgestein, In Sprengstofflose Festgesteinsgewinnung im Tagebau und im Bauwesen, Heft 89 der Schriftenreihe der GDMB. Freiberg, 2003, ISBN 3-935797-13-3.

[2] P. Schmieder, and C. Drebenstedt, Sprengstofflose Gewinnungsverfahren - Methodik zur Bewertung von Umwelteinflüssen. Die Naturstein-Industrie, 2005 (jetzt MIRO), 41, 2, S. 23-29.

[3] P. Schmieder, and C. Drebenstedt, Sprengstofflose Gewinnung im Festgestein - Möglichkeiten und Grenzen, In Cement International, 2005, 31, S. 58-74.

[4] M. Ataei, M. Jamshidi, F. Sereshki, and S.M.E. Jalali, Mining method selection by AHP approach". The Journal of the Southern African Institute of Mining and Metallurgy, 2008, Vol. 108

[5] G.M. Foderà, A. Voza, G. Barovero, F. Tinti, and D. Boldini, Factors influencing overbreak volumes in drill-and-blast tunnel excavation. A statistical analysis applied to the case study of the Brenner Base Tunnel - BBT, The Journal of Tunnelling and Underground Space Technology, 2020, Vol.105, Nov., 103475

[6] H.K. Vivek, A.K. Mishra, M.P. Roy, K.V. Ashish, and P.K. Singh, Numerical simulation based approach for assessment of blast induced deformation pattern in slot raise excavation, International Journal of Rock Mechanics and Mining Sciences, 2021, Vol. 144, Aug., 104816

[7] A. Ali, and H. Mohammed, A review of some nonexplosive alternative methods to conventional rock blasting, Open Geosciences 2021; 13: 431-442

[8] K. Rakesh, V.M.S.R. Murthy, and L.A. Kumaraswamidhas, Performance analysis of rotary blast-hole drills through machine vibration and coarseness index mapping - A novel approach, The Journal of Measurement, 2020, Vol. 165, 1 Dec., 108148

[9] E.S. Namin, K. Shahriar, M. Ataee-Pour, and H. Dehghani, A new model for mining method selection of mineral deposit based on fuzzy decision making, Journal of the South African Institute of Mining and Metallurgy, 2008, 108(7), 385-395.

[10] D. Oluwatobi, G. Bekir, and O. Moshood, Technology adoption in mining: A multi-criteria method to select emerging technology in surface mines, Resources Policy 69 (2020) 101879.

[11] E. Gomaa, and C. Drebenstedt, Statistical analysis fuzzy and environmental accounting methods for evaluate the underwater mining equipment, Scientific Reports on Resource Issues. Innovations in Mineral IndustryGeology, Mining, Metallurgy, and Management, 2011, Freiberg, Germany. P 313-324.
[12] E. Gomaa, and C. Drebenstedt, The environmentally innovations and development occur on aquatic mining equipment and techniques, 20th International Symposium of Mining Planning and Equipment Selection MPES 2011, Almaty, Kazakhstan.

[13] T. Xu-Qing, L. Yang, L. Wei-Wei, and S. Wanqiang, "A novel method for constructing the optimal hierarchical structure based on fuzzy granular space Journal of Applied Soft Computing 87 (2020).

[14] S. Fernando, J.C. Jan, and R.B. Pablo, An integrated constrained fuzzy stochastic analytic hierarchy process method with application to the choice problem Expert Systems with Applications, 138 (2019) 112822.

[15] C.B. Bhanu, and K.G. Amit, Sensitivity analysis of fuzzyanalytic hierarchical process (FAHP) decision making model in selection of underground metal mining method, Journal of Sustainable Mining 18 (2019) 8-17.

[16] A. Mohammad, M. Reza, H. Seyed, and M.H. Seyed, Fuzzy analytical hierarchy process approach for ranking the sawability of carbonate rock" International Journal of Rock Mechanics \& Mining Sciences 50 (2012) 83-93.

[17] M. Yavuz, The application of the analytic hierarchy process (AHP) and Yager's method in underground mining methods election problem. International Journal of Mining, Reclamation and Environment, 2015, 29(6),453-475.

[18] L.A. David, P. Rodrigo, K.O. Coco, and C. Elianna, Assessment of mining activity on arsenic contamination in surface water and sediments in southwestern area of Santurban paramo, Colombia, Journal of Environmental Management, 2020, 264 (2020) 110478.

[19] P.S. Elnaz, and A.D. Soroush, Developing a decision support system for logistics service provider selection employing fuzzy MULTIMOORA \& BWM in mining equipment manufacturing, 2020, Applied Soft Computing, 106849.

[20] V.D. Baloyi, and L.D. Meyer, The development of a mining method selection model through a detailed assessment of multi-criteria decision methods, Results in Engineering 2020, 100172.

[21] W. Dingyi, D. Cuifeng, L. Yifan, C. Baomeng, and W. Yuan, Thermal environment assessment of deep mine based on analytic hierarchy process and fuzzy comprehensive evaluation, Case Studies in Thermal Engineering, 19 (2020) 100618.

[22] Y. Xiong, Z. Guang-Ming, C. Gui-Qiu, T. Lin, W. Ke-Lin, and H. Dao-You, Combining AHP with GIS in synthetic evaluation of eco-environment quality, A case study of Hunan Province, China. Ecological Modelling, 2007, Vol. 209, Iss. 2-4, Pages 97-109.

[23] L. Sun, and W. Gu, Pavement Condition Assessment Using Fuzzy Logic Theory and Analytic Hierarchy Process, Journal of Transportation Engineering, 2011, 137(9), 648-655.

[24] K. Fatemeh, B. Ataallah, and A.S. Jafar, Mineral processing plant site selection using integrated fuzzy cognitive map and fuzzy analytical hierarchy process approach: A case study of gilsonite mines in Iran, Minerals Engineering, 2020, 147 (2020) 106143.

[25] Q. Rui, L. Sha, Q. Lu, S. Li, and G. Chengzhu, Critical factors to green mining construction in China: A two-step fuzzy DEMATEL analysis of state-owned coal mining 
enterprises Journal of Cleaner Production, 2020, 273

(2020) 122852.

[26] T.L. Saaty, The analytic hierarchy process: Planning, priority setting, resource allocation. New York, 1980, McGraw-Hill.

[27] Z. Ya., Y. Fen, and S. Min, Appraisal of Logistics Enterprise Competitiveness on the Basis of Fuzzy Analysis Algorithm, The Journal of American Science, 2005, 1(2).

[28] Z. Xin, H. Long, Z. Jing, D. Matthew, M.K. Whiting, and Z. Qin, Determination of key canopy parameters for mass mechanical apple harvesting using supervised machine learning and principal component analysis (PCA), Biosystems engineering, 193 (2020) 247 e263.

[29] G. Nicolas, E.M. Ryan, and B.S. Oliver, Classification of fentanyl analogues through principal component analysis (PCA) and hierarchical clustering of GC-MS data, Forensic Chemistry, 21 (2020) 100287.

[30] A. Solomon, S. Chuanbo, Y.Z. Yao, M.R. Mercy, and Z. Xiangfeng, Principal component analysis (PCA) based hybrid models for the accurate estimation of reservoir water saturation, Computers \& Geosciences, 145 (2020) 104555. 